Primljen / Received: 9.5.2016.

Ispravljen / Corrected: 8.3.2017.

Prihvaćen / Accepted: 10.4.2017.

Dostupno online / Available online: 10.12.2017.

\section{Layered finite elements in the analysis of composite structures exposed to long-term effects}

Authors:

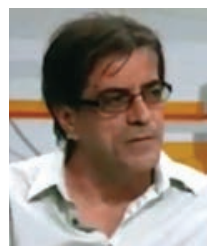

Andelko Cumbo, PhD. CE

Institute for urbanism, civil engineering and ecology of R. Srpska, Banja Luka

andjelko.cumbo@gmail.com

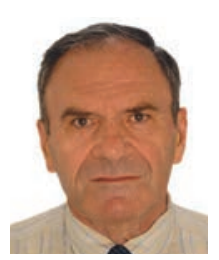

Prof. Radomir Folić, PhD. CE

University of Novi Sad

Faculty of Technical Sciences

folic@uns.ac.rs

\section{Andelko Cumbo, Radomir Folić}

Subject review

Layered finite elements in the analysis of composite structures exposed to long-term effects

This paper presents the use of a numerical model based on layered finite elements in the analysis of stress and strain due to creep and shrinkage of concrete and relaxation of prestressing steel in statically indeterminate composite structures. The calculation algorithm allows significant changes in the structure through characteristic time intervals, in accordance with technological procedures used during realisation of works. The corresponding computer program adapted to daily practical engineering design is also developed.

Key words:

finite elements, composite structures, creep and shrinkage, relaxation, rheology

Pregledni rad

Andelko Cumbo, Radomir Folić

Uslojeni konačni elemenati u proračunu spregnutih konstrukcija izloženih dugotrajnim djelovanjima

U radu je predložen jedan numerički proračunski model za analizu stanja naprezanja i deformacija zbog puzanja i skupljanja betona i relaksacije čelika za prednapinjanje kod statički neodređenih spregnutih konstrukcija utemeljen na uslojenim konačnim elementima. Algoritam proračuna omogućava da se kroz karakteristične vremenske intervale uvedu sve bitne promjene u konstrukciji u skladu s tehnološkim postupcima pri izvođenju radova. Razvijen je i odgovarajući računalni program prilagođen inženjerskim proračunima u praksi.

Ključne riječi:

konačni elementi, spregnute konstrukcije, puzanje i skupljanje, relaksacija, reologija

Übersichtsarbeit

Andelko Cumbo, Radomir Folic

Geschichtete finite Elemente zur Berechnung von Verbundkonstruktionen bei langanhaltenden Einwirkungen

In dieser Arbeit wird ein auf geschichteten finiten Elementen beruhendes numerisches Berechnungsmodell für die Analyse des durch Schwinden und Kriechen des Betons sowie durch die Relaxation der Bewehrung verursachten Spannungs- und Dehnungszustands bei statisch unbestimmten Verbundkonstruktionen eingeführt. Der Berechnungsalgorithmus ermöglicht, dass durch kurze Zeitintervalle alle entscheidenden Veränderungen in der Konstruktion im Einklang mit technologischen Verfahren bei der Ausführung erfasst werden. Es wurde auch ein entsprechendes für Ingenieursberechnungen in der Praxis angepasstes Computerprogramm entwickelt.

Schlüsselwörter:

finite Elemente, Verbundkonstruktionen, Kriechen und Schwinden, Relaxation, Rheologie 


\section{Introduction}

A composite girder (CG) consists of two or more elements made of materials of different properties, which are structurally merged along the height of cross-section. CGs composed of steel and concrete are the most frequently encountered composite girder arrangements used in civil engineering. Engineers usually try to make the maximum use of the best properties of steel and concrete parts of the composite. It is known that highly optimal CGs can be obtained by assuming tensile stress with steel, and compressive stress with concrete. This enables realisation of elegant and slender structures, which are highly manufactured, with convenient quality of fabrication and built-in materials [1]. Various CG shapes can be formed depending on the type and extent of coupling of the concrete and steel composite. Depending on the technological procedure used in the process, coupling can be executed either for the overall or partial structural and service load, with or without pre-stressing the concrete and/ or steel girder. This is usually achieved by applying an overall or partial support when constructing the composite structure (CS) in phases. Composite elements can be executed using stiff, elastic or discontinuous couplings, which primarily depends on conditions during construction and use of the structure. The elastic and discontinuous couplings are specific types of couplings where favourable stress and strain distributions can be achieved across the CG cross section. However, in this paper the analysis is focused on the stiff steel-concrete composites, where yielding in the joint is not assumed to occur, and where there are no relative horizontal displacements of the contact surface between the steel and concrete, so that failure occurs by reaching the critical bending load, instead by shearing at the contact surface between composite elements. It is also assumed that the concrete part will assume the compression stress, and that the occurrence of tensile stresses and cracks practically excludes concrete from bearing the load. For this type of coupling it can be assumed with sufficient accuracy that the stress-strain ratio in the area of operating stresses $\left(\sigma_{c} \leq 0,4 f_{c k}\right)$ is linear and that the assumption about the equality of strain at contact points between two materials is properly justified.

It is known that shrinkage and creep of concrete can over time significantly influence the change of stress and strain in CSs [2]. In the area of operating stresses, strain due to creep of concrete can be brought in an approximately linear relationship with stresses - linear creep theory, and in calculation creep is assumed to be independent from external load. These strains can be two to three, or even more times greater compared to elastic strain, and so it is very important to include these changes in the calculation and to ensure proper usability and durability of CSs, in addition to capacity, taking also into account the potentially different time intervals of inclusion of certain parts / layers in the stress activity.

In the area of linear creep theory, stress and strain ratios are provided in integral / differential forms, and these equations can not be resolved in closed form even for very simple stress/ strain histories. Therefore, practical issues are mainly resolved using numerical methods, and the problem is reduced to solving a system of algebraic equations. Analysing the stress and strain in statically indeterminate CSs is a more complex task because, over time, rheological properties of materials induce changes in response, and thus in cross-sectional forces, even without change in load. Basic calculations of statically indeterminate structures using the method of forces are presented in [2] with the introduction of viscoelastic properties of the material, and using the algebraic stress-strain relationship for concrete. These efforts were followed by development of calculation models based on the method of strain, and methods which used the discretization of structures on elements of finite dimensions. The finite element method (FEM) [3] is the best known and most widely used where, instead of differential equations, simple algebraic equations are established, whose matrix shape is highly suitable for programming and computer use.

A comprehensive and broad overview of methods for long-term analysis, including procedures defined in EN 1992, EN 1994-11, and EN 1994-2, is presented in [4] and [5]. An overview of the state-of-the-art in the wider area of design and analysis of steel-concrete composite structures, with a specific focus on determination of the effective slab width, is presented in [6].

A calculation model using the FEM method is developed in this paper. Here, the stiffness matrix of the FE is applied using the layer method in cross-section, and the effects due to viscous properties of the material are introduced through a fictitious load [7]. The application of incremental forms of the stressstrain relation for individual materials allows the procedure for discontinuous and continuous changes to be generalized by introducing fictitious and finite time intervals [8]. This reduces the overall calculation procedure to the resolution of algebraic equations in matrix form, which is convenient for programming and automation of the calculation process.

\section{Incremental stress-strain relations}

\subsection{Incremental relation for concrete}

It is known that concrete is a highly elastoplastic material that deforms under load. For finding mathematical stress-strain relations, idealized bodies or mechanical rheological models are used in theoretical rheology. For short-term loads in the elastic range, the relation is identified using the well-known Hooke's law. However, long-term load leads to an increase in strain, even when stress is not increased. These strains increase with the duration of the load, and when load is applied to green concrete. Such strains are referred to in literature as creep strain in concrete. This is a complicated phenomenon requiring a complex mathematical interpretation [9]. For practical problems, the stress-strain relation is based on the linear creep theory. This theory starts from specific assumptions:

- Concrete is treated as a homogeneous and isotropic material; - Current elastic strain of concrete is proportional to stress, 
and depends on the age of concrete (variable modulus of elasticity);

- Shrinkage of concrete is independent of stress, but is the consequence of the hardening process;

- Creep of concrete is linearly dependent on the long-term influence of stress;

- Boltzmann's principle of superposition can be applied to creep strain.

In general, the total strain of concrete $\varepsilon_{\mathrm{c}}(\mathrm{t})$ occurring over time $t$ is linearly dependent on the stress $\sigma_{c}$ and amounts to [10]:

$\varepsilon_{\mathrm{c}}(\mathrm{t})=\sigma_{\mathrm{c}} \cdot \varphi(\mathrm{t}, \tau)$

where $\varphi(t, \tau)$ is the function of the creep of concrete and represents the total strain in time interval $t$ under constant unit stress $\sigma_{c}=1$, which acts starting from moment $t=\tau$. If the concrete cross-section is exposed to variable stress as the continuous function in time interval $t_{0}-t$, then, based on the assumption about the superposition of strains, the total strains can be written as follows [8]

$\varepsilon_{\mathrm{c}}(\mathrm{t})-\varepsilon_{\mathrm{cn}}(\mathrm{t})=\int_{\mathrm{t}_{0}}^{\mathrm{t}} \varphi(\mathrm{t}, \tau) \cdot \mathrm{d} \sigma(\tau)$

where $\varepsilon_{\mathrm{cn}}(t)$ is the strain of concrete at the moment $t$ independent of the stress, such as shrinkage or thermal strain.

The accuracy of results depends on the shape of the function of creep. Although there are a variety of theories of creep of concrete and analytical models for the function of creep, they will not be considered here due to space limitations.

Resolving the integral equation (2) requires numerical integration. For this purpose, the total time interval $\left(t-t_{0}\right)$ should be divided into subintervals $\Delta t_{i}=t_{i}-t_{i-1},(i=1,2, \ldots, k)$, in which the calculation is conducted successively (Figure 1). In doing so, abrupt changes in stress are included using fictitious (zero) intervals $\Delta t_{i}=0$, which enables generalization of the calculation procedure.

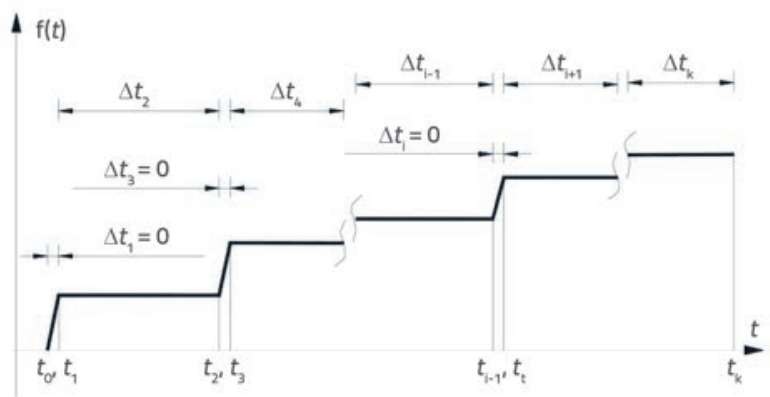

Figure 1. Time discretization

By forming a sub-integral in incremental form and applying some of the known methods of numerical integration, the stress-strain ratio for concrete can be expressed in the following form [8]:
$\Delta \varepsilon_{\mathrm{c}}\left(\mathrm{t}_{\mathrm{k}}\right)=\frac{\Delta \sigma_{\mathrm{c}}\left(\mathrm{t}_{\mathrm{k}}\right)}{E_{\mathrm{c}(\mathrm{k}, \mathrm{k}-1)}}+\Delta \varepsilon_{\mathrm{c}}^{*}\left(\mathrm{t}_{\mathrm{k}}\right)$

where $\Delta \varepsilon_{c}\left(t_{k}\right)$ is the free strain of concrete and is given by:

$\Delta \varepsilon_{\mathrm{c}}^{*}\left(\mathrm{t}_{\mathrm{k}}\right)=\sum_{\mathrm{i}=1}^{\mathrm{k}-1} \frac{\Delta \sigma_{\mathrm{c}}\left(\mathrm{t}_{\mathrm{i}}\right)}{E_{\mathrm{c}(\mathrm{k}, \mathrm{i}-1)}^{*}}+\Delta \varepsilon_{\mathrm{cn}}\left(\mathrm{t}_{\mathrm{k}}\right)$

$E_{c(k, k-1)}$ represents the generalized, and $E_{c(k, k-1)}$ the derived deformation modulus of concrete, which depends on the type of numerical integration that is used for the adopted function of the creep of concrete. These modules are related using the following expression:

$\frac{1}{E_{\mathrm{c}(\mathrm{k}, \mathrm{i}-1)}^{*}}=\frac{1}{E_{\mathrm{c}(\mathrm{k}, \mathrm{i}-1)}}-\frac{1}{E_{\mathrm{c}(\mathrm{k}-1, \mathrm{i}-1)}}$

where is:

$\Delta \varepsilon_{c}\left(t_{k}\right)$ - increase of strain of concrete in the current $k$-th time interval

$\Delta \varepsilon_{\mathrm{cn}}\left(t_{k}\right)$ - increase of shrinkage of concrete in the current $k$-th time interval

$\Delta \sigma_{c}(t)$ - increase of stress in concrete in the $i$-th time interval $(i=1,2, \ldots, k-1)$.

Equation (3) represents a unique generalized form as all known stress-strain ratio forms for concrete can be applied including the Age-adjusted effective modulus method (AAEM method; Bazant, 1972). Thus, the course of calculation in the fictitious and finite intervals for the arbitrary history of external influences is unified regardless of the number of subintervals. More accurate calculations require a greater number of subintervals and computer application. However, with the successive application of the AAEM method, for simple load histories an acceptable accuracy can be achieved even with a minimum number of subintervals.

Using expression (3), the current final time intervals are included in a full recursive expression, and in the fictitious interval the corresponding module is reduced to the modulus of elasticity, and the free strain of concrete is then equal to zero. This is actually the well known form of the stress-strain ratio for elastic state (Hooke's relation). Expression (4) provides the change of free strain of concrete in the current $k$-th time interval, from the previous stress history to the interval under consideration (without the influence of the $k$-th part of the stress history), along with the increment of shrinkage of concrete in the current $k$-th interval only.

\subsection{Incremental ratio for prestressing steel}

The pure (inherent) relaxation of prestressing steel (PS) can be defined as a drop in the initial tensile stress over a certain period of time at constant strain. However, in operating conditions 
the strains in CG are variable over time, and so the strains in PS are also variable. By applying the incremental stress-strain ratio, these changes may be covered with sufficient accuracy for common practical problems [11]. The generalized form of the incremental ratio for PS can be written as:

$\Delta \sigma_{\mathrm{p}}\left(\mathrm{t}_{\mathrm{k}}, \mathrm{t}_{\mathrm{k}-1}\right)=E_{\mathrm{p}} \cdot \Delta \varepsilon_{\mathrm{p}}\left(\mathrm{t}_{\mathrm{k}}, \mathrm{t}_{\mathrm{k}-1}\right)+\Delta \bar{\sigma}_{\mathrm{pr}}\left(\mathrm{t}_{\mathrm{k}}, \mathrm{t}_{\mathrm{k}-1}\right)$

where $\Delta \bar{\sigma}_{\mathrm{pr}}\left(t_{k^{\prime}} t_{k-1}\right)$ is the change in stress due to the relaxation under variable strain, i.e. reduced relaxation of PS.

The increase in reduced relaxation can be represented as a product of two independent functions. The first function introduces the influence of the corrected stress discrete moments of the observed interval, while the second introduces the change in reduced relaxation over the past period of time. The simplified incremental form of reduced relaxation can assume the following form:

$\bar{\sigma}_{\mathrm{pr}}\left(\mathrm{t}_{\mathrm{k}}, \mathrm{t}_{\mathrm{k}-1}\right)=f_{1} \bar{\sigma}_{\mathrm{p}}\left(\mathrm{t}_{\mathrm{k}}\right) \cdot f_{2}\left(\mathrm{t}_{\mathrm{k}}-\mathrm{t}_{0}\right)-f_{1} \bar{\sigma}_{\mathrm{p}}\left(\mathrm{t}_{\mathrm{k}-1}\right) \cdot f_{2}\left(\mathrm{t}_{\mathrm{k}-1}-\mathrm{t}_{0}\right)$

where the corrected stresses for discrete moments of the observed interval assume the following form:

$$
\begin{aligned}
& \bar{\sigma}_{\mathrm{p}}\left(\mathrm{t}_{\mathrm{k}-1}\right)=\sigma_{\mathrm{p}}\left(\mathrm{t}_{\mathrm{k}-1}\right)-\Delta \bar{\sigma}_{\mathrm{pr}}\left(\mathrm{t}_{\mathrm{k}-1}, \mathrm{t}_{0}\right)=E_{\mathrm{p}} \cdot \varepsilon_{\mathrm{p}}\left(\mathrm{t}_{\mathrm{k}-1}-\mathrm{t}_{0}\right) \\
& \bar{\sigma}_{\mathrm{p}}\left(\mathrm{t}_{\mathrm{k}}\right)=\sigma_{\mathrm{p}}\left(\mathrm{t}_{\mathrm{k}}\right)-\Delta \bar{\sigma}_{\mathrm{pr}}\left(\mathrm{t}_{\mathrm{k}}, \mathrm{t}_{0}\right)=E_{\mathrm{p}} \cdot \varepsilon_{\mathrm{p}}\left(\mathrm{t}_{\mathrm{k}}-\mathrm{t}_{0}\right)
\end{aligned}
$$

In determining the incremental relaxation, all values are known from the previous calculation step, with the only unknown being the corrected stress for the current step of calculation. This requires an iterative procedure, but appropriate simplifications can be introduced for practical use. Assuming that the corrected stress in the current time interval is constant, all values are known, which makes the aforementioned iterations unnecessary. Additional simplifications can also be introduced by using inherent relaxation instead of reduced relaxation, and by using actual stress for the preceding discrete moment instead of corrected stress, that is, by ignoring the effect of relaxation on the value of the initial corrected stress. In addition, the PS relaxation can also be introduced in calculation through simplified relation with the reduced modulus of elasticity [12] This approximate approach procedure is on the side of safety, and the following expression is applied:

$\Delta \sigma_{\mathrm{p}}\left(\mathrm{t}_{\mathrm{k}}, \mathrm{t}_{\mathrm{k}-1}\right)=\left(1-\rho_{\mathrm{p}}\right) \cdot E_{\mathrm{p}} \cdot \Delta \varepsilon_{\mathrm{p}}\left(\mathrm{t}_{\mathrm{k}}, \mathrm{t}_{\mathrm{k}-1}\right)=E_{\mathrm{p}}^{*} \cdot \Delta \varepsilon_{\mathrm{p}}\left(\mathrm{t}_{\mathrm{k}}, \mathrm{t}_{\mathrm{k}-1}\right)$

In the above expression, the reduced modulus of elasticity $E_{p}$ appears in the following form:

$E_{p}^{*}=\left(1-\rho_{p}\right) \cdot E_{p}$

where $\rho_{\mathrm{p}}$ is the factor of relaxation that is most commonly specified in engineering regulations. This is usually the value of pure relaxation for the respective PS.
In discontinuous changes, fictitious (zero) time intervals are introduced, and then the incremental relaxation is equal to zero. It does not require any changes to the generalized expression, which is suitable when using matrix forms of equations and designing program packages.

\subsection{Incremental ratios for structural steel and soft concrete steel}

For the steel part of composite cross-section - structural steel (SS) and non-tensile steel (mild steel, mild reinforcement - MS), a linear stress-strain ratio is assumed according to Hooke's law for all time subintervals:

$$
\begin{aligned}
& \Delta \sigma_{\mathrm{a}}\left(\mathrm{t}_{\mathrm{k}}\right)=E_{\mathrm{a}} \cdot \Delta \varepsilon_{\mathrm{a}}\left(\mathrm{t}_{\mathrm{k}}\right) \\
& \Delta \sigma_{\mathrm{s}}\left(\mathrm{t}_{\mathrm{k}}\right)=E_{\mathrm{s}} \cdot \Delta \varepsilon_{\mathrm{s}}\left(\mathrm{t}_{\mathrm{k}}\right)
\end{aligned}
$$

Matrix forms of expressions (1) through (6) are used in the following part of the paper, with component strains $\Delta \varepsilon_{\mathrm{r}}$ and $\Delta \kappa$, and the corresponding stress components $\Delta \alpha_{r}$ and $\Delta \beta$ [13].

\section{Equilibrium equation in composite girder cross-section}

Consider a composite girder (CG) of known cross-sectional dimensions, load, mechanical properties of materials, and known conditions of development of shrinkage and creep of concrete. The cross-section can be described with equilibrium equations of internal and external forces, and the conditions of compatibility of strains and the constitutive stress-strain relations can be determined. Thus, the Bernoulli-s hypothesis of flat cross-sections (the linearity of strain distribution across the height of the cross-section) is assumed to be valid. The strain linearity is valid across the entire cross-section, and the abrupt change in the overall strain may be a result of inclusion of individual parts / materials of the composite section in the stress activity at different times (Figure 2).

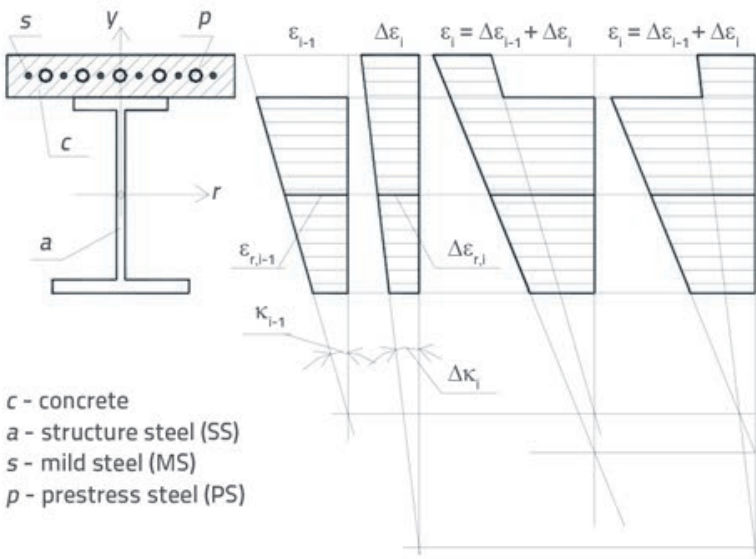

Figure 2. Cross-section and strain values in composite girder 
However, for the incremental form of equations, the increase in strain is a linear function for all active parts of cross-section, so that in a general case the following is valid [8]

$\Delta \varepsilon_{\mathrm{k}}=\Delta \varepsilon_{\mathrm{c}, \mathrm{k}}=\Delta \varepsilon_{\mathrm{a}, \mathrm{k}}=\Delta \varepsilon_{\mathrm{s}, \mathrm{k}}=\Delta \varepsilon_{\mathrm{p}, \mathrm{k}}=\Delta \varepsilon_{\mathrm{r}, \mathrm{k}}+\Delta \kappa_{\mathrm{k}} \cdot \mathrm{y}$

gdje su:

$\Delta \varepsilon_{\mathrm{k}}$ - increase of strain in the observed fibre of cross-section for the current time interval

$\Delta \varepsilon_{\mathrm{r}, \mathrm{k}}$ - increase of strain in the level of reference cross-sectional axis $r(y=0)$

$\Delta \kappa_{\mathrm{k}}$ - cross-sectional curvature

$y \quad$ - istance of the observed fibre from the reference axis $r$.

In accordance with the linear distribution of strains, stresses along the height of the cross-section are distributed linearly. However, the increase in stress in each part of the composite cross-section (c-concrete, a-SS, s-MS, $p$-PS) is defined by a specific pair of parameters $\Delta \alpha_{r, k}$ and $\Delta \beta_{k}$ in accordance with the constitutive stress-strain ratios. When writing the expressions in vector form, the equations assume the following form [13]:

$\left|\begin{array}{c}\Delta \alpha_{\mathrm{r}} \\ \Delta \beta\end{array}\right|_{\mathrm{a}, \mathrm{k}}=E_{\mathrm{a}}\left|\begin{array}{c}\Delta \varepsilon_{\mathrm{r}} \\ \Delta \kappa\end{array}\right|_{\mathrm{a}, \mathrm{k}}$

$\left|\begin{array}{c}\Delta \alpha_{\mathrm{r}} \\ \Delta \beta\end{array}\right|_{\mathrm{s}, \mathrm{k}}=E_{\mathrm{s}}\left|\begin{array}{c}\Delta \varepsilon_{\mathrm{r}} \\ \Delta \kappa\end{array}\right|_{\mathrm{s}, \mathrm{k}}$

$\left|\begin{array}{c}\Delta \alpha_{\mathrm{r}} \\ \Delta \beta\end{array}\right|_{\mathrm{c}, \mathrm{k}}=E_{\mathrm{c}(\mathrm{k}, \mathrm{k}-1)}\left(\left|\begin{array}{c}\Delta \varepsilon_{\mathrm{r}} \\ \Delta \kappa\end{array}\right|-\left|\begin{array}{c}\Delta \varepsilon_{\mathrm{r}}^{*} \\ \Delta \kappa^{*}\end{array}\right|\right)_{\mathrm{c}, \mathrm{k}}$

$\left|\begin{array}{c}\Delta \alpha_{\mathrm{r}} \\ \Delta \beta\end{array}\right|_{\mathrm{p}, \mathrm{k}}=E_{\mathrm{p}}\left|\begin{array}{c}\Delta \varepsilon_{\mathrm{r}} \\ \Delta \kappa\end{array}\right|_{\mathrm{p}, \mathrm{k}}+\left|\begin{array}{c}\Delta \bar{\sigma}_{\mathrm{pr}} \\ 0\end{array}\right|_{\mathrm{p}, \mathrm{k}}$

When the shrinkage is equal at all points along the height of the cross-section, the vector of changes in free strains has the following form:

$\left|\begin{array}{c}\Delta \varepsilon_{\mathrm{r}}^{*} \\ \Delta \kappa^{*}\end{array}\right|_{\mathrm{c}, \mathrm{k}}=\sum_{\mathrm{i}=1}^{\mathrm{k}-1} \frac{1}{E_{\mathrm{c}(\mathrm{k}, \mathrm{i}-1)}^{*}}\left|\begin{array}{c}\Delta \alpha_{\mathrm{r}} \\ \Delta \beta\end{array}\right|_{\mathrm{c}, \mathrm{i}}+\left|\begin{array}{c}\Delta \varepsilon_{\mathrm{n}} \\ 0\end{array}\right|_{\mathrm{c}, \mathrm{k}}$

For the $k$-th time interval and the adopted reference axis $r$, two conditions of equilibrium of external and internal forces can be established in the cross section: for the sum of forces in the direction of the girder's longitudinal axis, and for the sum of bending moments around the reference axis. After integration of the established conditions and arrangement of terms, the relation between the change in strains and change in forces in the current time interval can be expressed as:
$\mathrm{K}_{\mathrm{k}} \cdot\left|\begin{array}{l}\Delta \varepsilon_{\mathrm{r}} \\ \Delta \kappa\end{array}\right|_{\mathrm{k}}=\left|\begin{array}{l}\Delta N \\ \Delta M\end{array}\right|_{\mathrm{k}}-\left|\begin{array}{l}\Delta N^{*} \\ \Delta M^{*}\end{array}\right|_{\mathrm{c}, \mathrm{k}}-\left|\begin{array}{l}\Delta N^{*} \\ \Delta M^{*}\end{array}\right|_{\mathrm{p}, \mathrm{k}}$

The stiffness matrix of the cross-section is:

$\mathbf{K}_{\mathrm{k}}=E_{\mathrm{c}(\mathrm{k}, \mathrm{k}-1)} \mathbf{D}_{\mathrm{c}}+E_{\mathrm{a}} \mathbf{D}_{\mathrm{a}}+E_{\mathrm{s}} \mathbf{D}_{\mathrm{s}}+E_{\mathrm{p}} \mathbf{D}_{\mathrm{p}}$

where the matrices of geometrical characteristics of individual cross-section components assume the following form:

$\mathbf{D}_{\mathrm{m}}=\left|\begin{array}{ll}A & S \\ S & I\end{array}\right|_{\mathrm{m}} \quad \mathrm{m}=\mathrm{c}, \mathrm{a}, \mathrm{s}, \mathrm{p}$

The stiffness matrix is variable in time only due to change in the generalized strain modulus of concrete $E_{c(k, k-1)}$, while other components are constant in all time intervals. A special case is the inclusion of individual parts of the cross-section in the stress activity at different times, which is an additional reason for the change in the stiffness matrix of the composite cross-section formed in this way. The vector of change in fictitious forces, due to rheological characteristics of concrete and the PS, is:

$\left|\begin{array}{l}\Delta N^{*} \\ \Delta M^{*}\end{array}\right|_{\mathrm{c}, \mathrm{k}}=E_{\mathrm{c}(\mathrm{k}, \mathrm{k}-1)} \mathbf{D}_{\mathrm{c}}\left|\begin{array}{l}\Delta \varepsilon_{\mathrm{r}}^{*} \\ \Delta \kappa^{*}\end{array}\right|_{\mathrm{c}, \mathrm{k}}$

$\left|\begin{array}{l}\Delta N^{*} \\ \Delta M^{*}\end{array}\right|_{\mathrm{p}, \mathrm{k}}=\left|\begin{array}{l}A \\ S\end{array}\right|_{\mathrm{p}} \Delta \bar{\sigma}_{\mathrm{pr}, \mathrm{k}}$

The present calculation algorithm for given values of forces in the cross section has no specific additional limitations. Discontinuous changes are introduced through fictitious time intervals and these are special cases, where the expressions are reduced to standard elastic forms of relations. However, in statically indeterminate girders, due to rheological properties of concrete and PS, a change of forces occurs in cross-sections even without the change in load. The changes in these forces can not be taken into account by analysing the state in crosssection as previously illustrated. Instead, the structure should be analysed as a whole system. Such complex analyses are mostly conducted using the method of forces and the method of strain, for which the basic equations of elasticity are extended as equations of viscoelasticity [2]. However, only the development of numerical methods has provided the convenience for the generalisation of calculation models and use of computers.

\section{Equilibrium equation of composite layered finite element}

The application of FEM requires discretization of the continuum into elements of finite dimensions. The set of all finite elements 
(FE) interconnected in nodes forms the mesh of FE of the structure under consideration. In the established system of algebraic equations, dimensions related to element nodes are taken as unknown dimensions [3]. The use of the FEM for the problem under study requires introduction of a number of assumptions [13]:

- The analysis relates to linear finite elements which in general case form a composite concrete and steel part, with additional PS and MS. It is assumed that a full coupling is achieved, i.e. the equality of increase in strain $\left(\Delta \varepsilon_{c, k}=\Delta \varepsilon_{a, k}=\Delta \varepsilon_{s, k}=\Delta \varepsilon_{p, k}=\Delta \varepsilon_{k}\right)$ applies for the current $k$-th time interval;

- Bernoulli's assumption of straight cross-sections holds, as well as the linearity of change of strain along the height of the composite cross-section (the influence of shear on strain in the FE can be ignored);

- Discretization is carried out along the length of the structural element; the contribution of the curve is introduced in the layers along the height of the cross-section in addition to axial strain, while the contribution of the cross-section rotation is ignored;

- Composite elements are approximated using the straight-line FE in the $x O y$ plane, where an arbitrary point in an element has three degrees of freedom of movement: horizontal displacement $\mathrm{u}(\mathrm{x})$, vertical displacement $\mathrm{v}(\mathrm{x})$, and rotation of the cross-section $\mathrm{j}(x)$. When nodal displacements are taken as unknown dimensions, the linear finite element has, in general case, six degrees of freedom, and three unknown generalized displacements in each node $\left(u_{1}, v_{1^{\prime}} \varphi_{1^{\prime}} u_{2^{\prime}} v_{2^{\prime}}, \varphi_{2}\right)$ (Figure 3).

$\Delta Y$

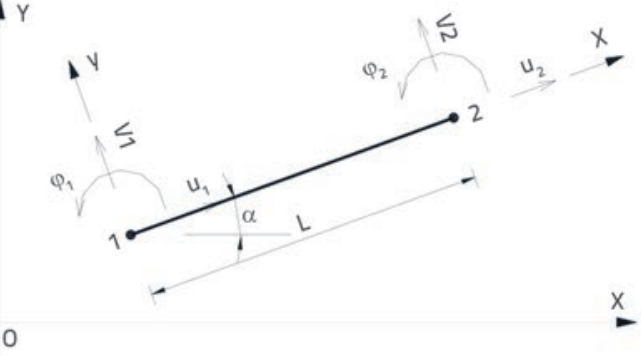

Figure 3. Linear finite element

The following rule on signs has been applied: $u$ and $v$ displacements, $\mathrm{N}$ and $\mathrm{T}$ - forces, stresses s and the corresponding strains $\varepsilon_{\text {, }}$ are positive in the direction of positive axis of the coordinate system. Rotation, $\varphi$, bending moment, $\mathrm{M}$, inclination of stress diagram, $\beta$, and curvature, $\kappa$, are positive when their rotational direction is counter clockwise. Stresses and strains are related to the local coordinate system only. According to this rule, shrink strains of concrete $\varepsilon_{\text {cn }}$ in the initial (first) node of the analysed FE are positive, while they are negative in the final (second) node. The same rule applies to the change in stress $\Delta \sigma_{\mathrm{pr}}$ during relaxation of PS.

The incremental relation between the components of strain (strains and curves) and displacement (longitudinal and transverse) of the analysed FE in the current $k$-th time interval, in the form of transposition, can be expressed as follows:
$\left|\begin{array}{l}\Delta \varepsilon(\mathrm{x}) \\ \Delta \kappa(\mathrm{x})\end{array}\right|_{\mathrm{k}}=\left|\begin{array}{ll}\frac{\mathrm{d} \Delta u_{\mathrm{T}}(\mathrm{x})}{\mathrm{d} x} & \frac{\mathrm{d}^{2} \Delta v(\mathrm{x})}{\mathrm{d} x^{2}}\end{array}\right|_{\mathrm{k}}^{\top}$

Changes of parameters of displacement along the elements $\Delta \mathrm{u}(x)$ and $\Delta \mathrm{v}(x)$ are defined through the assumed displacement field of FE. The displacement field is determined using interpolation functions (functions of form) [3]. The interpolation matrices $\mathbf{N}$ are defined by assuming that cross-sectional rotation is the corresponding derivative of displacement, i.e. that $\Delta \varphi(x)_{k}=-\delta v(x)_{k} / \delta x$. These matrices relate the vector of displacement $\Delta q(x)_{k}$ in the field of the element and the vector of nodal displacements $\Delta \mathrm{q}_{k}$ in the analysed $k$-th time interval. Based on differential relations given in expression (25), a relation can be established between the strain components along the rod axis and the displacements of nodal points of components:

$\left|\begin{array}{l}\Delta \varepsilon(\mathbf{x}) \\ \Delta \kappa(\mathbf{x})\end{array}\right|_{\mathrm{k}}=\left|\frac{\mathrm{d}}{\mathrm{d} x}\left(\mathbf{N}_{u} \mathbf{q}_{u}\right)-\frac{\mathrm{d}^{2}}{\mathrm{~d} x^{2}}\left(\mathbf{N}_{v} \mathbf{q}_{v}\right)\right|_{\mathrm{k}}^{\top}$

If it is assumed that the displacement of nodal point FE relates to the displacement of the point in the reference axis $r$, and by applying the corresponding derivatives in expression (26) using shorter annotations, a relation is established between the primary strain values $\Delta \varepsilon_{\mathrm{r}}$ and $\Delta \kappa$ of points of the element field and the vector of nodal displacements $\Delta \mathbf{q}_{\mathrm{r}}$ as follows:

$\left|\begin{array}{c}\Delta \varepsilon_{\mathrm{r}} \\ \Delta \kappa\end{array}\right|_{\mathrm{k}}=\mathbf{B}_{\mathrm{r}} \Delta \mathbf{q}_{r, \mathrm{k}}$

where the matrix $\mathbf{B}_{\mathrm{r}}$ has the following coefficients:

$\mathbf{B}_{\mathrm{r}}=\left|\begin{array}{cccccc}-\frac{1}{L} & 0 & 0 & \frac{1}{L} & 0 & 0 \\ 0 & \frac{6}{L^{2}}-\frac{12 x}{L^{3}} & \frac{4}{L}-\frac{6 x}{L^{2}} & 0 & -\frac{6}{L^{2}}+\frac{12 x}{L^{3}} & \frac{2}{L}-\frac{6 x}{L^{2}}\end{array}\right|_{r}$

In line with the adopted assumption of straight cross-sections, the dilation in an arbitrary point of cross-section where the matrix $\mathbf{B}_{r}$ has the following coefficients: is determined from the following expression:

$\Delta \varepsilon_{\mathrm{k}}=\left(\Delta \varepsilon_{r}+\Delta \kappa y\right)_{\mathrm{k}}=\left.\left|\begin{array}{ll}1 & y\end{array}\right| \begin{gathered}\Delta \varepsilon_{\mathrm{r}} \\ \Delta \kappa\end{gathered}\right|_{\mathrm{k}}=\mathbf{P}\left|\begin{array}{c}\Delta \varepsilon_{\mathrm{r}} \\ \Delta \kappa\end{array}\right|_{\mathrm{k}}$

When inserting equation (33) in (35), the strain in an arbitrary point of the FE cross-section has the following form:

$\Delta \varepsilon_{\mathrm{k}}=\mathbf{P B}_{r} \Delta \mathbf{q}_{\mathrm{r}, k}=\mathbf{G} \Delta \mathbf{q}_{\mathrm{r}, k}$

where matrix $\mathbf{G}$ for dilation of an arbitrary point has the following coefficients: 
$\mathbf{G}=\left|-\frac{1}{L}\left(\frac{6}{L^{2}}-\frac{12 x}{L^{3}}\right) y\left(\frac{4}{L}-\frac{6 x}{L^{2}}\right) y \quad \frac{1}{L}\left(-\frac{6}{L^{2}}+\frac{12 x}{L^{3}}\right) y\left(\frac{2}{L}-\frac{6 x}{L^{2}}\right) y\right|$

The matrix format of expression (30) represents the relation between the increase of strain $\Delta \varepsilon_{k}$ in the arbitrary point in the field FE and the increase of displacement of its nodes in the analysed $k$-th time interval. All the above facts apply to all component materials (c-concrete, a-SS, s-MS, $p$-PS).

In line with the adopted assumption of full (rigid) coupling, where the increments of strain of all parts / layers of the composite cross-section in the analysed reference axis are equal to each other, the equality of displacement for the current $k$-th time interval is also true:

$\Delta \mathbf{q}_{r, c, k}=\mathbf{q}_{r, a, k}=\mathbf{q}_{r, s, k}=\mathbf{q}_{r, p, k}=\mathbf{q}_{r, k}$

After substituting equations (30) in equation (3), and bearing in mind the above equality of displacements, the incremental relation between stresses and nodal displacements of the concrete part of the cross-section has the following form:

$\Delta \sigma_{\mathrm{c}, \mathrm{k}}=E_{\mathrm{c}(\mathrm{k}, \mathrm{k}-1)} \mathbf{G}\left(\Delta \mathbf{q}_{\mathrm{r}, k}-\Delta \mathbf{q}_{\mathrm{r}, \mathrm{c}, \mathrm{k}}^{*}\right)$

where the relation between the free strains and free displacements assumes the following form:

$\Delta \varepsilon_{\mathrm{c}, \mathrm{k}}^{*}=\mathbf{G} \Delta \mathbf{q}_{\mathrm{r}, c, k}^{*}$

Incremental relations for other layers / materials of the composite element can be written in a similar way:

$\Delta \sigma_{\mathrm{a}, \mathrm{k}}=E_{\mathrm{a}} \mathbf{G} \Delta \mathbf{q}_{\mathrm{r}, k}$

$\Delta \sigma_{\mathrm{s}, \mathrm{k}}=E_{\mathrm{s}} \mathbf{G} \Delta \mathbf{q}_{\mathrm{r}, k}$

$\Delta \sigma_{\mathrm{p}, \mathrm{k}}=E_{\mathrm{p}} \mathbf{G} \Delta \mathbf{q}_{\mathrm{r}, k \mathrm{k}}+\Delta \bar{\sigma}_{\mathrm{pr}, \mathrm{k}}$

The theoretical foundation on which the FEM relies is the principle of minimum energy in varying displacements, that is, the principle of equality in increment of operation of external forces on predefined displacements and the increment of operation of internal forces on respective strains [3]. In the general case, the operations must be summed up for all layers / materials of the composite element (c-concrete, a-SS, s-MS, $p$-PS). Expressions are further derived using the corresponding replacements, virtual displacements and Lagrange's theorem. By transforming the matrix products under the integrals (scalars) and using the stance about the minimum total potential energy change $\delta \Delta \Pi=0$, and by differentiating the term $\Delta \mathbf{q}_{\mathrm{rk}}^{\top}$ we obtain that:

$\mathbf{K}_{k} \Delta \mathbf{q}_{r, k}+\Delta \mathbf{Q}_{c, k}^{*}+\Delta \mathbf{Q}_{p, k}^{*}=\Delta \mathbf{Q}_{k}$

where is:

$\mathrm{K}_{\mathrm{k}}$ - stiffness matrix of the composite FE
$\Delta \mathbf{Q}_{\mathrm{k}}$ - vector of external nodal forces

$\Delta \mathbf{Q}_{c, k}^{*}$ - vector of fictitious nodal forces due to creep and shrinkage of concrete

$\Delta Q_{p, k}^{*}$ - vector of fictitious nodal forces due to relaxation of PS.

Expression (38) represents the generalized condition of equilibrium of the linear layered (composite) FE in the local coordinate system.

\subsection{Stiffness matrix of layered finite element}

The stiffness matrix of the composite FE $\left(\mathbf{K}_{k}\right)$, for the general case, written as the sum of proportions of concrete, SS, MS and $P S$, is:

$\mathbf{K}_{k}=\mathbf{K}_{c, k}+\mathbf{K}_{a, k}+\mathbf{K}_{s, k}+\mathbf{K}_{p, k}$

After the integration, the stiffness matrix coefficients for individual layers / materials of the composite FE assume the following form (indices $c, a, s, p$ are replaced with index $m$ ):

$$
\mathbf{K}_{m, k}=\frac{E_{\mathrm{m}}}{L^{3}}\left|\begin{array}{cccccc}
A_{\mathrm{m}} L^{2} & 0 & -S_{\mathrm{m}} L^{2} & -A_{\mathrm{m}} L^{2} & 0 & S_{\mathrm{m}} L^{2} \\
& 12 I_{\mathrm{m}} & 6 I_{\mathrm{m}} L & 0 & -12 I_{\mathrm{m}} & 6 I_{\mathrm{m}} L \\
& & 4 I_{\mathrm{m}} L^{2} & 0 & -6 I_{\mathrm{m}} L & 2 I_{\mathrm{m}} L^{2} \\
& & & A_{\mathrm{m}} L^{2} & 0 & -S_{\mathrm{m}} L^{2} \\
& & & & 12 I_{\mathrm{m}} & -6 I_{\mathrm{m}} L \\
& & & & & 4 I_{\mathrm{m}} L^{2}
\end{array}\right|_{k}
$$

Stiffness matrix coefficients (40) differ from stiffness matrix coefficients of the homogeneous rod by the member $\mathrm{E}_{\mathrm{m}, \mathrm{k}} \mathrm{S}_{\mathrm{m}, \mathrm{k}} / \mathrm{L}$. The dimension $S_{m, k}$ is the static momentum of the crosssectional surface relative to the reference axis $r$. This is the member through which the influence of the height position of individual layers in the composite cross-section is introduced.

\subsection{Vectors of nodal forces for layered finite element}

The vector of nodal forces coming from external load in the transposed form (for the ease of display) is:

$\Delta \mathbf{Q}_{k}=\left|\begin{array}{llllll}\Delta N_{1} & \Delta T_{1} & \Delta M_{1} & \Delta N_{2} & \Delta T_{2} & \Delta M_{2}\end{array}\right|_{\mathrm{k}}^{\top}$

In line with the FEM concept, the load of the element field is replaced by equivalent nodal force components. Correspondingly, any arbitrary element load can be replaced with an equivalent nodal load [3]. The vector of fictitious nodal forces of the concrete part of cross-section is:

$\Delta \mathbf{Q}_{c, k}^{*}=\left|\begin{array}{llllll}\Delta N_{1}^{*} & \Delta T_{1}^{*} & \Delta M_{1}^{*} & \Delta N_{2}^{*} & \Delta T_{2}^{*} & \Delta M_{2}^{*}\end{array}\right|_{c, k}^{T}=-\mathbf{K}_{c, k} \Delta \mathbf{q}_{r, c, k}^{*}$

The emergence of fictitious nodal forces is in accordance with changes in the element due to shrinkage and creep of concrete in the given interval. These forces may also 
be given physical interpretation [13]. According to the definition, free strains, or free displacements, are caused by shrinkage and creep of concrete, rather than by direct action of external loads. Assuming that concrete displacements are temporarily prevented by introduction of fictitious internal connections, gradual changes occur in the stress, i.e. in fictitious forces, due to rheological properties of concrete. These forces cancel free displacements. As the analysed fictitious element lacks conditions that prevent the occurrence of free displacements, it is necessary to remove these conditions, i.e. it is necessary to apply negative values of fictitious forces in nodes in which the effect of reaction of fictitious conditions is cancelled.

The direct determination of fictitious forces using the right-hand side of equation (42) for the adopted $\mathrm{FE}$ model first requires definition of the vector of free displacement of nodal points $\Delta \mathbf{q}_{r, c, k}^{*}$ . However, these displacements cannot be determined from expressions (33) and (34) because $\mathbf{G}^{-1}$ is unknown. In conditions defined in this way, fictitious forces can only be determined based on the free strains in the concrete part of cross-section. Therefore, in the process of arranging the expression, the part of equation (38) that defines fictitious forces should be taken a step back:

$\Delta \mathbf{Q}_{c, k}^{*}=-\mathbf{K}_{\mathrm{c}, \mathrm{k}} \Delta \mathbf{q}_{r, c, k}^{*}=-\int_{V_{c}} \mathbf{G}^{T} E_{\mathrm{c}(\mathrm{k}, \mathrm{k}-1)} \mathbf{P}\left|\begin{array}{c}\Delta \varepsilon_{r}^{*} \\ \Delta \kappa^{*}\end{array}\right|_{\mathrm{c}, \mathrm{k}} \mathrm{d} V_{\mathrm{c}}$

Free deformations in the concrete part of cross-section can be defined from the matrix form of equation (4), where the component $\Delta \kappa$ defines the change of strain along the height of cross-section. According to basic FEM postulates, these cross-sections refer to cross-sections in the nodes of elements. However, determining fictitious forces based on equation (43) requires integration across the volume of the element's concrete part / layer. This requirement, in addition to knowing the changes in strain along the height, also involves knowing changes in strain along the element. In line with the adopted FEM model, the external load of the element field is replaced with equivalent forces in nodal points. By introducing the function of form, a relation is established between the displacement of points in the element field and the displacement of nodal points. The relation between the free deformations in the element field and the corresponding values of these deformations at the ends of the rod, that is, in nodes 1 and 2 of the element, can be established in a similar way. Sufficient accuracy is achieved by using the linear relation, i.e. functions across the $x$ variable:

$\left|\begin{array}{c}\Delta \varepsilon_{r}^{*} \\ \Delta \kappa^{*}\end{array}\right|_{\mathrm{c}, \mathrm{k}}=\left|\begin{array}{l}\Delta \varepsilon_{r 1}^{*} \\ \Delta \kappa_{1}^{*}\end{array}\right|_{\mathrm{c}, \mathrm{k}}+\left(\left.\begin{array}{l}\Delta \varepsilon_{r 2}^{*} \\ \Delta \kappa_{2}^{*}\end{array}\right|_{\mathrm{c}, \mathrm{k}}-\left|\begin{array}{l}\Delta \varepsilon_{r 1}^{*} \\ \Delta \kappa_{1}^{*}\end{array}\right|_{\mathrm{c}, \mathrm{k}}\right) \frac{x}{L}$

The substitution of expression (44) in (43) and its integration determines the components of nodal fictitious forces:

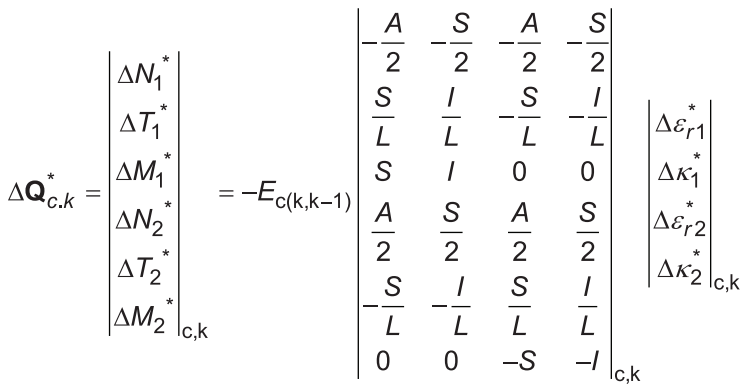

Using expression (45), the fictitious forces are completely determined. The static moment of the $S_{c, k}$ surface introduces the influence of the height position of the concrete part / material relative to the reference axis. The fictitious normal forces are constant and averaged along the analysed $\mathrm{FE}$, which is in line with the adopted assumptions. This averaging affects accuracy of the calculation procedure. By adopting a more refined division and increasing the number of finite elements, the accuracy of the calculation model also increases. The increment vector of fictitious forces due to relaxation of PS is:

$\Delta \mathbf{Q}_{p, k}^{*}=\int_{V_{p}} \mathbf{G}^{\top} \Delta \bar{\sigma}_{p r, k} \mathrm{~d} V_{p}$

A sufficient accuracy is achieved when adopting a linear function across the variable $x$ for changes in relaxation:

$\Delta \bar{\sigma}_{\mathrm{pr}, \mathrm{k}}=\Delta \bar{\sigma}_{\mathrm{pr} 1, \mathrm{k}}+\left(\Delta \bar{\sigma}_{\mathrm{pr} 2, \mathrm{k}}-\Delta \bar{\sigma}_{\mathrm{pr} 1, \mathrm{k}}\right) \frac{X}{L}$

By substituting expression (47) in equation (46), we get:

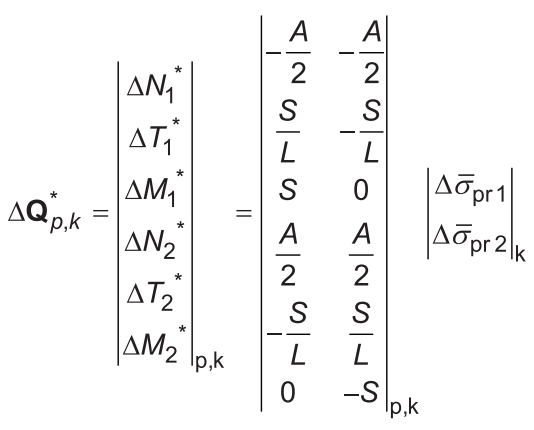

In this procedure, the influence of the height position of PS relative to the reference axis is introduced through the static moment of the $S_{p, k}$ surface. The fictitious normal forces are constant along the analysed $F E$, which is in line with the adopted assumptions. The physical interpretation of occurrence of fictitious forces due to relaxation of PS is analogous to what is described for the concrete part of cross-section. By applying negative values of total internal forces, the basic equation for the FE assumes the following form:

$\mathbf{K}_{\mathbf{k}} \Delta \mathbf{q}_{r, k}=\Delta \mathbf{Q}_{\mathrm{k}}-\Delta \mathbf{Q}_{c, k}^{*}-\Delta \mathbf{Q}_{p, k}^{*}$

where the stiffness matrix establishes a relation between nodal forces and nodal displacements. The previous equation is 
actually a system of algebraic equations, where the rheological properties of concrete and the PS are also introduced, in addition to the elastic characteristics of the material.

Discontinuous changes in load are introduced through fictitious time intervals $\Delta t_{k}=0$. Then zero values are obtained for fictitious forces. This case is actually a well-known system of equations for FEs with elastic properties of materials:

$\mathbf{K}_{\mathrm{k}} \Delta \mathbf{q}_{r, k}=\Delta \mathbf{Q}_{\mathrm{k}}$

The external load is usually unspecified for the finite time interval length $\left(\Delta t_{k}>0\right)$. Only fictitious forces are present. For this case, the basic equation for the FE will be reduced to the equation for viscoelastic materials:

$$
\mathbf{K}_{\mathbf{k}} \Delta \mathbf{q}_{r, k}=-\Delta \mathbf{Q}_{c, k}^{*}-\Delta \mathbf{Q}_{p, k}^{*}
$$

\section{Equilibrium equations for finite element systems}

The application of the finite-element method implies that the analysed structure (system) be divided into elements that form a FE mesh. In order to form a system of equations for the FE mesh, it is first of all necessary to set up basic equations for each FE. To set up an equilibrium equation for the system, the stiffness matrix and force vectors for each FE must be transformed from a local to a global coordinate system [3].

The system equilibrium equation (in matrix form) is obtained when the stiffness matrices and force vectors from the expression (49) for each KE are superimposed based on the criterion of interconnection of the system nodes [3]. The generalized equilibrium equation for the composite system as a whole is formed by placing the coefficients of the stiffness matrix and the force vectors of FE at the corresponding positions:

$\tilde{\mathbf{K}}_{\mathrm{k}} \Delta \tilde{\mathbf{q}}_{r, k}=\Delta \tilde{\mathbf{Q}}_{\mathrm{k}}-\Delta \tilde{\mathbf{Q}}_{c, k}^{*}-\Delta \tilde{\mathbf{Q}}_{p, k}^{*}$

The previous equation covers both the elastic and viscoelastic properties of composite materials. Viscoelastic changes are included using the time intervals of finite length $\left(\Delta t_{k}>0\right)$, while elastic (discontinuous) changes are included based on the fictitious time intervals $\left(\Delta t_{k}=0\right)$.

\subsection{Fictitious force vector of the system}

An error due to averaging axial forces for each FE for the general case of complex bending is introduced when calculating components of the fictitious force vector occurring due to the rheology of concrete and prestressed steel using expressions (45) and (48). This error is lower when the structural division is more refined. As average values are obtained using expressions
(45) and (48), the actual values of fictitious axial forces remain unknown (Figures 4 and 5), so that their distribution along each analysed $\mathrm{FE}$ is unknown.

At this point, an improvement has been introduced to the computational model, which increases the accuracy of results even without a substantial increase in the number of FEs in the system. This improved process starts by calculation of actual fictitious axial forces (Figures 4 and 5), which are then averaged and used in the calculation step in which the FEM equilibrium conditions must be satisfied. Averaged expansion values are calculated in the next step, which is followed by introduction of their repair in nodes (a process reverse to averaging).

In the analysed $F E$, actual values of fictitious axial forces can be obtained from expression (45) by excluding the influence of strain components of one node on another, i.e. when the corresponding stiffness matrix coefficients of the concrete layer assume a zero value:

$$
\Delta \mathbf{Q}_{c, k}^{*}=\left|\begin{array}{l}
\Delta N_{1}^{*} \\
\Delta T_{1}^{*} \\
\Delta M_{1}^{*} \\
\Delta N_{2}^{*} \\
\Delta T_{2}^{*} \\
\Delta M_{2}^{*}
\end{array}\right|_{\mathrm{c}, \mathrm{k}}=-E_{\mathrm{c}(\mathrm{k}, \mathrm{k}-1)}\left|\begin{array}{cccc}
-A & -S & 0 & 0 \\
\frac{S}{L} & \frac{I}{L} & -\frac{S}{L} & -\frac{I}{L} \\
S & I & 0 & 0 \\
0 & 0 & A & S \\
-\frac{S}{L} & -\frac{I}{L} & \frac{S}{L} & \frac{I}{L} \\
0 & 0 & -S & -I
\end{array}\right|_{\mathrm{c}, \mathrm{k}}\left|\begin{array}{c}
\Delta \varepsilon_{r 1}^{*} \\
\Delta \kappa_{1}^{*} \\
\Delta \varepsilon_{r 2}^{*} \\
\Delta \kappa_{2}^{*}
\end{array}\right|_{\mathrm{c}, \mathrm{k}}
$$

With fictitious forces calculated in this way, the equilibrium condition of the analysed FE in longitudinal direction is not satisfied. That is why the longitudinal force needs to be averaged in the next step of calculation (Figure 2):

$\Delta N_{1 \mathrm{c}, \mathrm{k}}^{*}=-\Delta N_{2 \mathrm{c}, \mathrm{k}}^{*}=\frac{\left(\Delta N_{\mathrm{N} 1 \mathrm{c}}^{*}-\Delta N_{\mathrm{N} 2 \mathrm{c}}^{*}\right)_{\mathrm{k}}}{2}$

The calculation model is illustrated by the example of the girder / beam where FEs are placed in succession / straight line (Figure 6.a). The diagram of bending moments in the first / fictitious time interval from the set load (current elastic state) is shown in Figure 3b. In the second / final time interval, the free deformations of the concrete part of cross-section (Figure 4) are calculated using expression (5), and then fictitious forces in FE nodes are determined from equation (53) (Figures 6.c and 6.d).

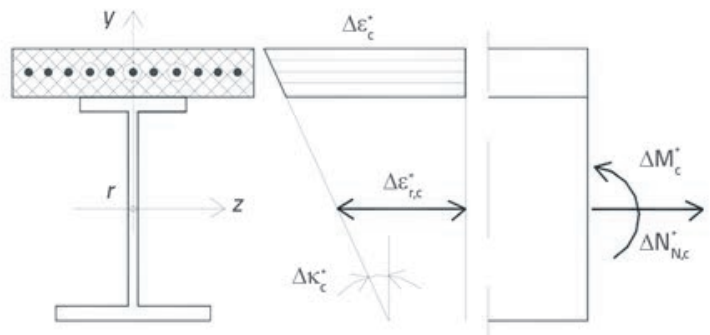

Figure 4. Free deformations in concrete and fictitious forces 


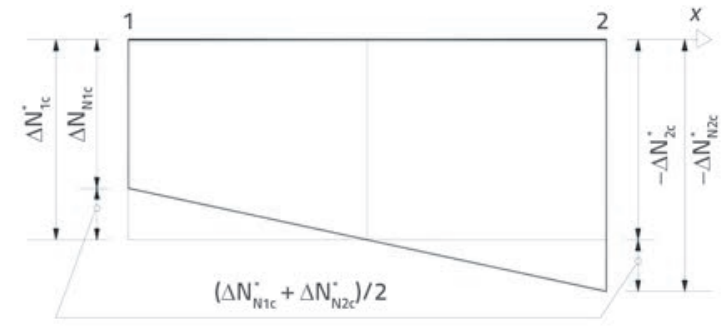

Figure 5. Fictitious axial forces of FE (actual and averaged)

In the second (final) time interval, fictitious axial forces are cancelled by adding up the forces belonging to the same node, since these forces are equal and opposite to one another in the cross-sectional node of two adjacent FEs (Figure 6.d). Fictitious bending moments are also cancelled (Figure 6.c), but only apparently, because these moments are adequately introduced in calculation through shear forces (Figure 6.f). If fictitious axial forces of each FE are not averaged, the contributions of these forces will not be accounted for in overall stresses and deformations. This would lead to significant deviations from the usual accuracy of calculation. According to the adopted model, the analysed FE lacks variable axial force. By averaging the values of axial forces according to expression (54), a stepwise diagram of these forces is obtained (Fig 6.e), so that the final values are obtained by adding them up in nodes (Figure 6.g). Thus, the contribution of the influence of fictitious axial forces is introduced in the subsequent calculation procedure, which leads to the results of acceptable accuracy.
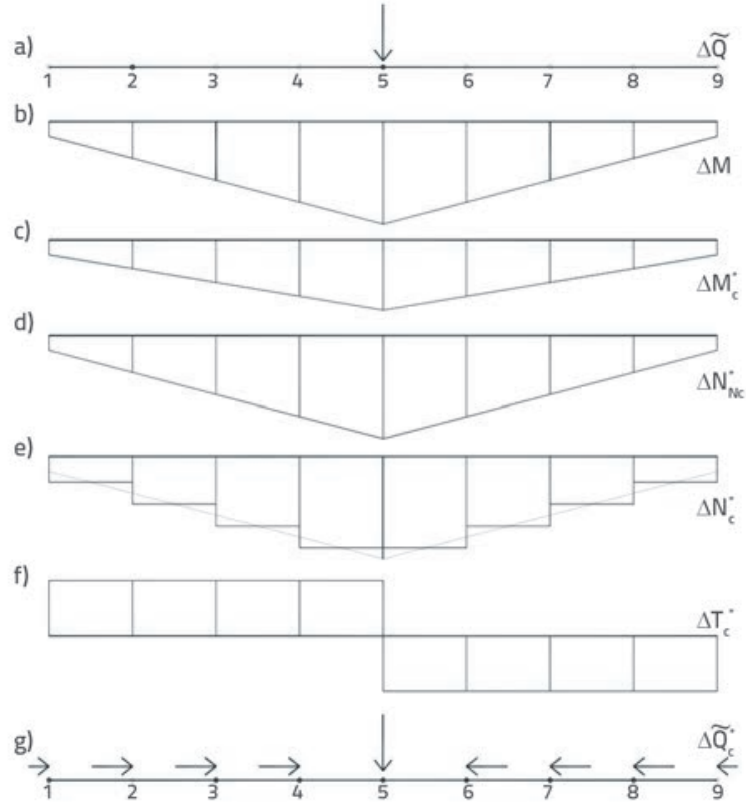

Figure 6. Fictitious forces of composite FEs in sequence/straight line

To increase the accuracy of calculation for systems with a lower number of FEs when calculating strain for the current time interval, an increase of strain $\Delta \varepsilon_{\mathrm{N}, \mathrm{k}}$ should be added (or subtracted) to (from) each averaged diagram of each analysed FE (Figures 5 and 6e):

$\Delta \varepsilon_{\mathrm{N}, \mathrm{k}}=\frac{1}{E_{\mathrm{r}} A_{\mathrm{k}}} \cdot\left(\frac{\Delta \mathrm{N}_{\mathrm{N} 1}^{*}+\Delta N_{\mathrm{N} 2}^{*}}{2}\right)_{\mathrm{k}}$

Thus an inclined diagram along the FE is formed once again, leading to an accuracy that is sufficient for usual practical analyses of composite structures. An analogous procedure also applies to the vector $\Delta Q_{\mathrm{p}, \mathrm{k}}^{*}$ due to relaxation of PS.

\section{Stress-deformation state}

Finding solution to the system of algebraic equations (52) enables determination of the vector of node displacement in the system for the current time interval. In the first step, it is necessary to introduce boundary conditions across the displacements and / or forces and eliminate the known conditions, because the stiffness matrix is singular. The strain in components of the analysed FE can be determined after setting apart the vector of displacement for its nodal points. These displacements should further be transformed from global to local coordinate system [3].

If the external load of the element field is introduced to the calculation through equivalent nodal forces, where the introduced elements are $\Delta \mathrm{M}_{\mathrm{M}}$ and if the fictitious normal forces $\Delta N_{M^{\prime}}$ are previously averaged, the part of $\operatorname{strain} \Delta \varepsilon_{N, k}$ and the part of curvature $\Delta \kappa_{\mathrm{M}, \mathrm{k}}$ will also be introduced in the calculation of the analysed FE:

$\left|\begin{array}{c}\Delta \varepsilon_{\mathrm{r}} \\ \Delta \kappa\end{array}\right|_{\mathrm{k}}=\mathbf{B}_{r} \Delta \mathbf{q}_{\mathrm{r}, \mathrm{k}}+\left|\begin{array}{c}\Delta \varepsilon_{\mathrm{N}} \\ \Delta \kappa_{\mathrm{M}}\end{array}\right|_{\mathrm{k}}$

In line with assumption on the equality of deformations, the calculated parameters of change in strain of the analysed FE apply to all cross-sectional layers / materials. However, stresses must be determined separately for each crosssectional layer using incremental forms of the stress-strain relation for individual materials (SS, MS, concrete and PS) given by expressions (15-18). Stresses along the height of individual layers are changing linearly, with abrupt changes occurring at contact surfaces between layers as a result of different physical and mechanical properties of materials.

Total stress and strain parameters for the discrete instant of time $t_{k}$ are determined by superposing the previous state and increment of state in the current time interval (step-by-step) for each layer / material $(m=a, c, s, p)$ :

$\left|\begin{array}{c}\alpha_{\mathrm{r}} \\ \beta\end{array}\right|_{\mathrm{k}}=\left|\begin{array}{c}\alpha_{\mathrm{r}} \\ \beta\end{array}\right|_{\mathrm{k}-1}+\left|\begin{array}{c}\Delta \alpha_{\mathrm{r}} \\ \Delta \beta\end{array}\right|_{\mathrm{k}}$ 


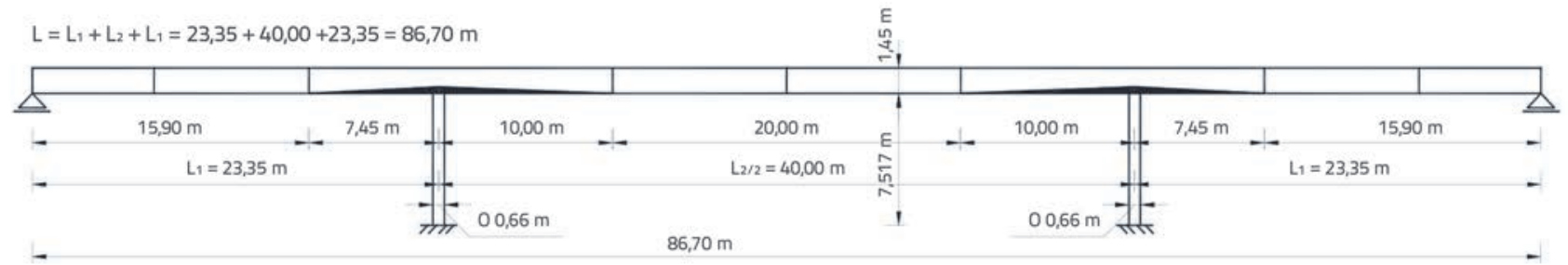

Figure 7. Longitudinal disposition of the bridge

$\left|\begin{array}{c}\varepsilon_{\mathrm{r}} \\ \kappa\end{array}\right|_{\mathrm{k}}=\left|\begin{array}{c}\varepsilon_{\mathrm{r}} \\ \kappa\end{array}\right|_{\mathrm{k}-1}+\left|\begin{array}{c}\Delta \varepsilon_{\mathrm{r}} \\ \Delta \kappa\end{array}\right|_{\mathrm{k}}$

For the parts / layers of the cross-section that are simultaneously included in the stress activity there is no abrupt change in total strain in the line of coupling. However, as the present calculation model supports subsequent inclusion of individual cross-sectional parts, depending on technological process used in execution, abrupt changes occur in the total strain at contact surfaces. The present calculation procedure is automated, and the authors developed a computer program that can resolve problems commonly encountered in engineering practice.

\section{Numerical analysis and discussion of results}

The application of the present calculation procedure is illustrated by the example of a continuous composite bridge frame structure $(L=23.35+40.00+23.35=86.70 \mathrm{~m})$ made of prestressed concrete products (Figure 7 - longitudinal cross-section, Figure 8 - cross-sections of the beam in the field and above the pillars) taken from [2] in order to check the accuracy of the developed calculation model. The beam is prestressed using cables consisting of 12 wires, each $5 \mathrm{~mm}$ in diameter. One cable introduces normal force of $\mathrm{P}=240 \mathrm{kN}$ into the beam in the centre of gravity of cables. The cables are arranged in seven groups marked with letters from $A$ to $G$ (Figures 9 and 10). Groups $A, C$, $D, F$ and $G$ contain straight-line cables. The maximum number of cables in group $A$ (cross-section 4 ) is 8 , in group $C$ (cross section 10) 64 , in group $D$ (cross-section 10 ) 28 , and in groups $F$ and $G$ (cross section 15) 8 (each). Groups B and E contain curved cables arranged along the ribs on the inward side of the box. Groups B and $E$ consists of 24 and 48 cables, respectively.

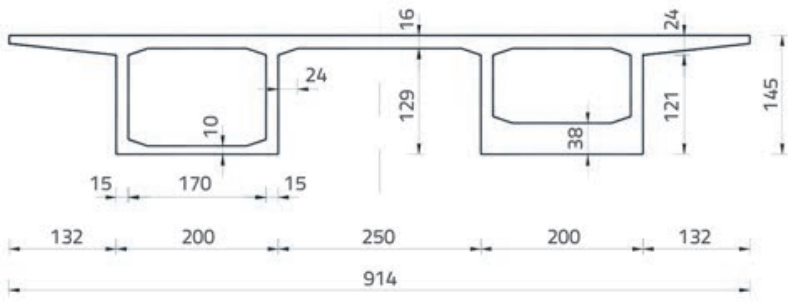

Figure 8. Transverse cross-sections of the beam in field and above pillars

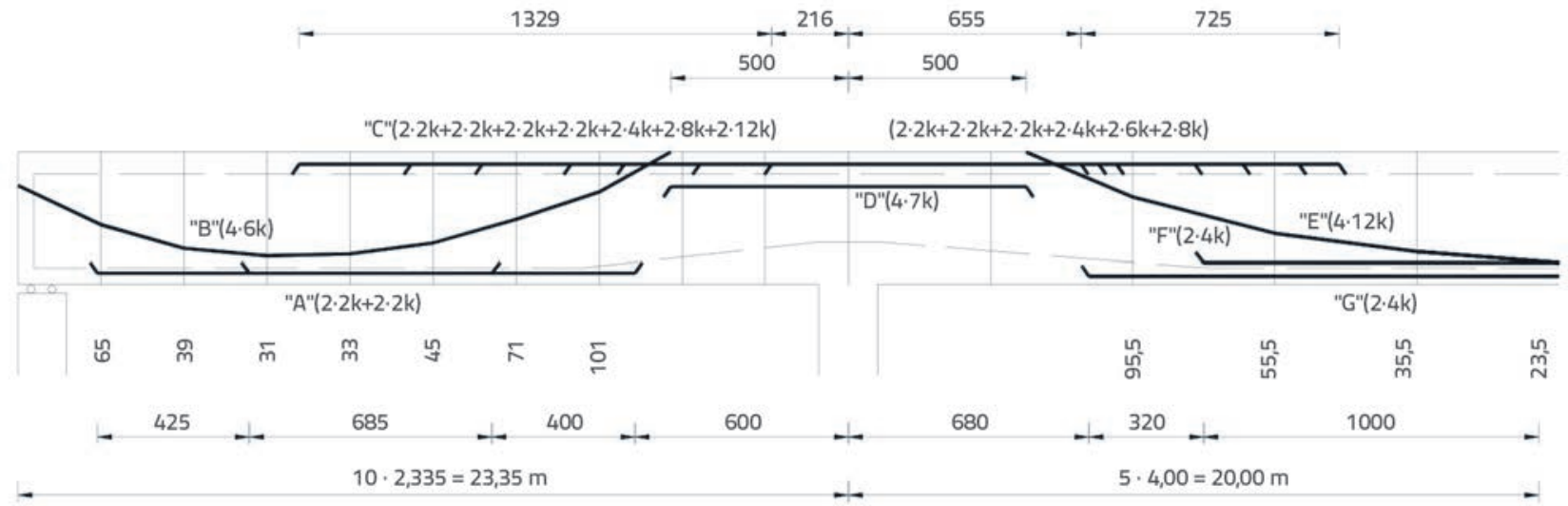

Figure 9. Longitudinal arrangement of cables
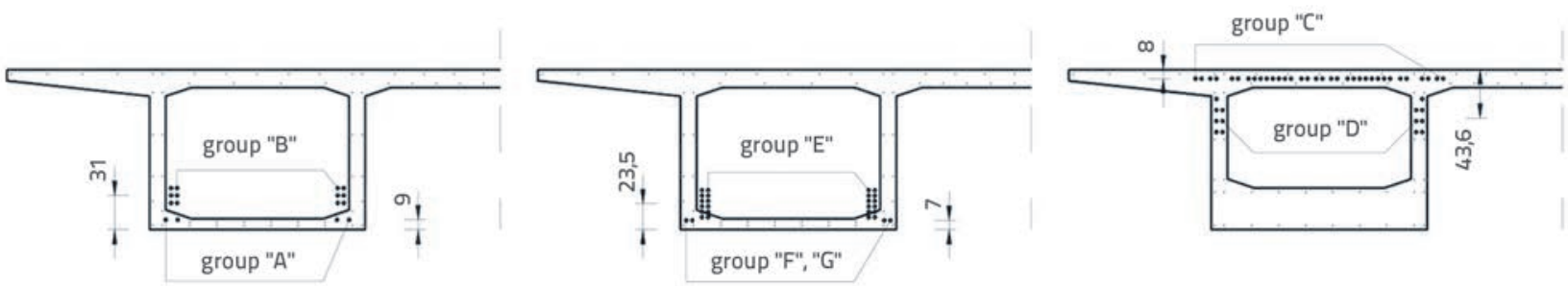

Figure 10. Arrangement of reinforcement and cables at cross-sections (a), (b) and (c) 

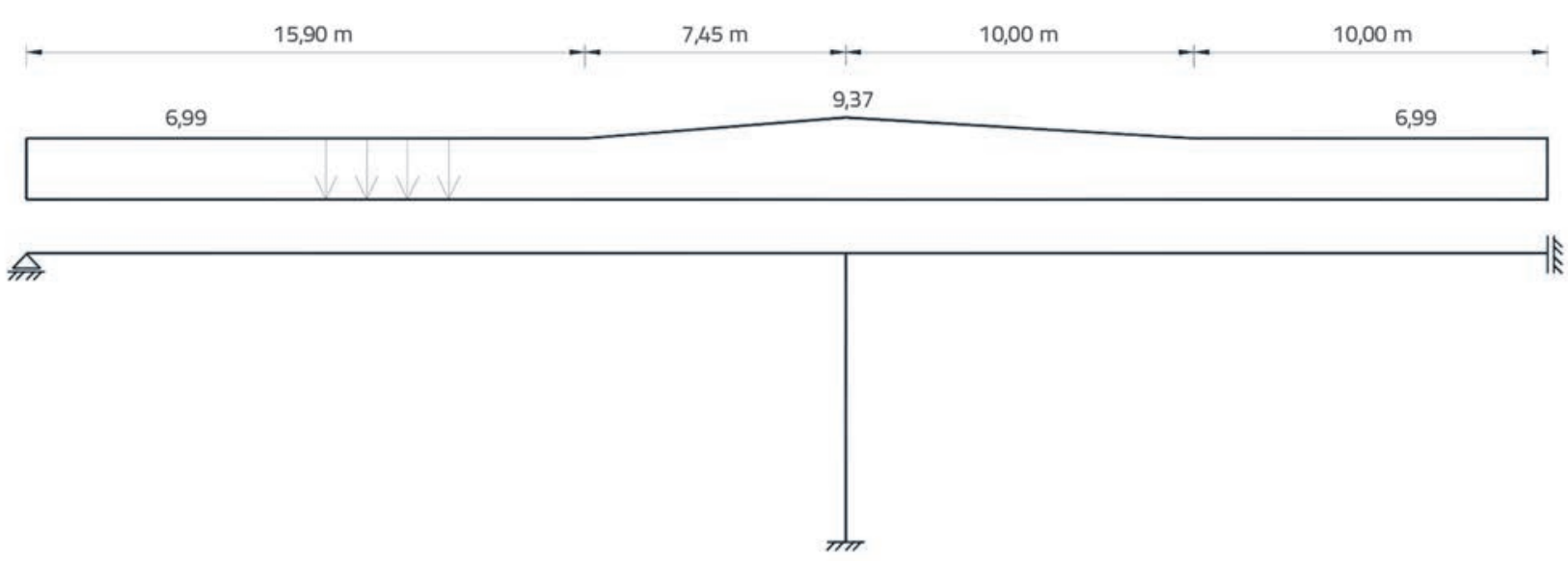

Figure 11. Continuous load of the girder
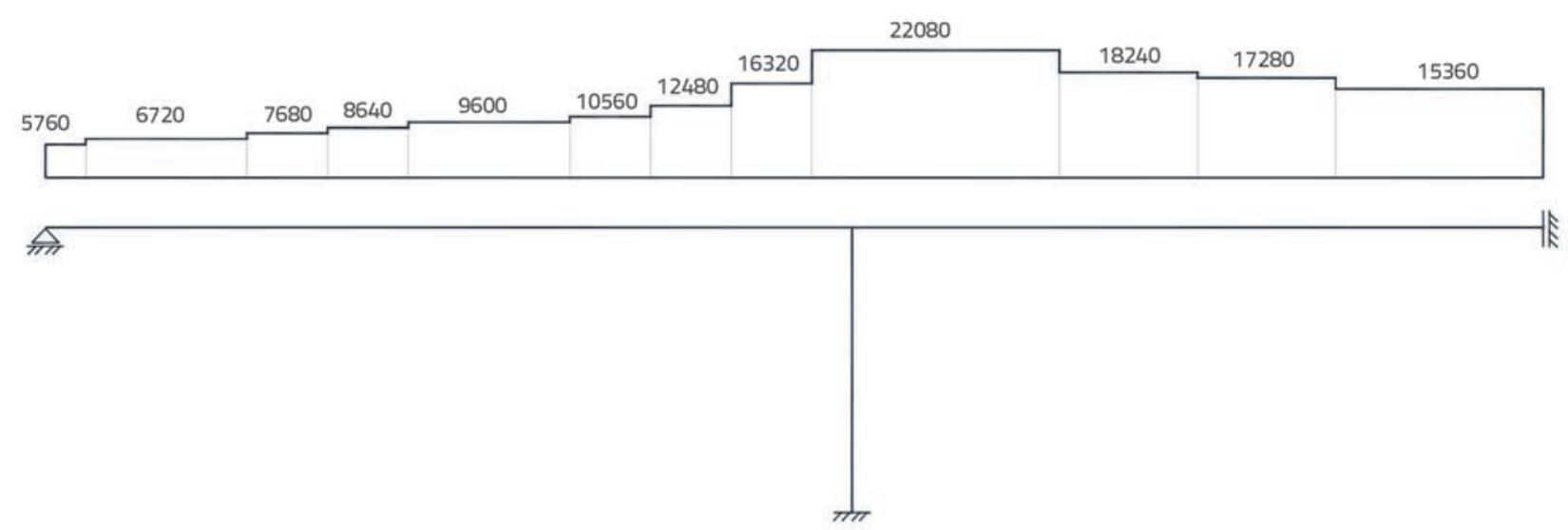

Figure 12. Arrangement of prestressing forces

The mild structural reinforcement of the beam is constant along the entire length and consists of $107 \phi 10$ and 8 \$14 reinforcing bars. The arrangement of this reinforcement is shown in the characteristic cross-sections of the beam (Figure 10).

Pillars are of circular cross-section $(\phi 66 \mathrm{~cm})$, placed under each box, and rigidly connected with the girder and the footings of foundation. The mild reinforcement of pillars consists of $28 \phi 20$ bars in the bottom part and $44 \phi 20$ bars in the top part.

The structure of the bridge is made of MB45 (C 35/45) concrete with the modulus of elasticity of $E_{c}=35 \mathrm{GPa}$. The coefficient of creep of concrete is taken to be $\varphi=2.0$, while the coefficient of shrinkage is taken as $\varepsilon_{\mathrm{n}}=2 \times 10^{-4}$. For the adopted algebraic relation of the method of average stress [2] the coefficient of aging should be taken as $\mathbf{c}=0.5$. The modulus of elasticity of the mild reinforcement is $E_{s}=210 \mathrm{GPa}$, while the modulus of elasticity of cables is $\mathrm{E}_{\mathrm{p}}=178.5 \mathrm{GPa}$.

The stress and strain state in the bridge structure has to be calculated to take into account the following actions:

- the structure's own weight (Figure 11)

- pre-stressing of the bay girder (Figure 12),

- concrete shrinkage.

The bridge structure should be executed in such a way that the structure is free from scaffolding at the time when the pre-

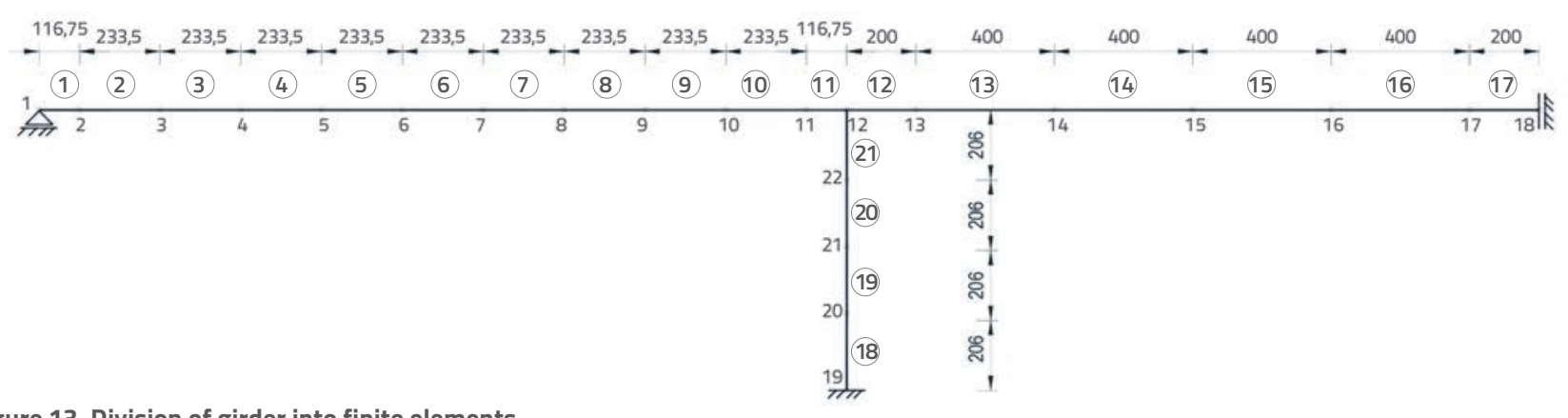

Figure 13. Division of girder into finite elements 
Table 1. Details on finite elements and their layers

\begin{tabular}{|c|c|c|c|c|c|c|c|c|c|c|}
\hline \multicolumn{2}{|c|}{ FE } & 1 & 2 & 3 & 4 & 5 & 6 & 7 & 8 & 9 \\
\hline 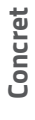 & $\begin{array}{l}A \\
I \\
Y_{T}\end{array}$ & $\begin{array}{l}2.79480 \\
0.76254 \\
0.46222\end{array}$ & $\begin{array}{l}2.79480 \\
0.76254 \\
0.46222\end{array}$ & $\begin{array}{l}2.79480 \\
0.76254 \\
0.46222\end{array}$ & $\begin{array}{l}2.79480 \\
0.76254 \\
0.46222\end{array}$ & $\begin{array}{l}2.79480 \\
0.76254 \\
0.46222\end{array}$ & $\begin{array}{l}2.79480 \\
0.76254 \\
0.46222\end{array}$ & $\begin{array}{l}2.79480 \\
0.76254 \\
0.46222\end{array}$ & $\begin{array}{l}2.89680 \\
0.83563 \\
0.49256\end{array}$ & $\begin{array}{l}3.16880 \\
0.98569 \\
0.55918\end{array}$ \\
\hline 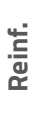 & $\begin{array}{l}A \\
I \\
Y_{T}\end{array}$ & $\begin{array}{l}0.00963 \\
0.00352 \\
0.67539\end{array}$ & $\begin{array}{l}0.00963 \\
0.00352 \\
0.67539\end{array}$ & $\begin{array}{l}0.00963 \\
0.00352 \\
0.67539\end{array}$ & $\begin{array}{l}0.00963 \\
0.00352 \\
0.67539\end{array}$ & $\begin{array}{l}0.00963 \\
0.00352 \\
0.67539\end{array}$ & $\begin{array}{l}0.00963 \\
0.00352 \\
0.67539\end{array}$ & $\begin{array}{l}0.00963 \\
0.00352 \\
0.67539\end{array}$ & $\begin{array}{l}0.00963 \\
0.00352 \\
0.67539\end{array}$ & $\begin{array}{l}0.00963 \\
0.00337 \\
0.66300\end{array}$ \\
\hline$\frac{0}{0}$ & $\begin{array}{l}A \\
I \\
Y_{T}\end{array}$ & $\begin{array}{l}0.00661 \\
0.00000 \\
0.46222\end{array}$ & $\begin{array}{l}0.00661 \\
0.00025 \\
0.87999\end{array}$ & $\begin{array}{l}0.00661 \\
0.00007 \\
1.10286\end{array}$ & $\begin{array}{l}0.00755 \\
0.00007 \\
1.19500\end{array}$ & $\begin{array}{l}0.00850 \\
0.00110 \\
1.05778\end{array}$ & $\begin{array}{l}0.00944 \\
0.00173 \\
0.88800\end{array}$ & $\begin{array}{l}0.00944 \\
0.00142 \\
0.60400\end{array}$ & $\begin{array}{l}0.01038 \\
0.00127 \\
0.39273\end{array}$ & $\begin{array}{l}0.01227 \\
0.00042 \\
0.27192\end{array}$ \\
\hline & FE & 10 & 11. 12 & 13 & 14 & 15 & 16 & 17 & 18. 19 & 20. 21 \\
\hline 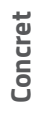 & $\begin{array}{l}A \\
I \\
Y_{T}\end{array}$ & $\begin{array}{l}3.44080 \\
1.08524 \\
0.60894\end{array}$ & $\begin{array}{l}3.74680 \\
1.15438 \\
0.64935\end{array}$ & $\begin{array}{l}3.33388 \\
1.05283 \\
0.59200\end{array}$ & $\begin{array}{l}2.96480 \\
0.87884 \\
0.51105\end{array}$ & $\begin{array}{l}2.79480 \\
0.76254 \\
0.46222\end{array}$ & $\begin{array}{l}2.79480 \\
0.76254 \\
0.46222\end{array}$ & $\begin{array}{l}2.79480 \\
0.76254 \\
0.46222\end{array}$ & $\begin{array}{l}0.68424 \\
0.01863 \\
0.00000\end{array}$ & $\begin{array}{l}0.68424 \\
0.01863 \\
0.00000\end{array}$ \\
\hline : & $\begin{array}{l}A \\
I \\
Y_{T}\end{array}$ & $\begin{array}{l}0.00963 \\
0.00330 \\
0.65680\end{array}$ & $\begin{array}{l}0.00963 \\
0.00320 \\
0.64637\end{array}$ & $\begin{array}{l}0.00963 \\
0.00333 \\
0.65941\end{array}$ & $\begin{array}{l}0.00963 \\
0.00344 \\
0.66854\end{array}$ & $\begin{array}{l}0.00963 \\
0.00352 \\
0.67539\end{array}$ & $\begin{array}{l}0.00963 \\
0.00352 \\
0.67539\end{array}$ & $\begin{array}{l}0.00963 \\
0.00352 \\
0.67539\end{array}$ & $\begin{array}{l}0.01759 \\
0.00059 \\
0.00000\end{array}$ & $\begin{array}{l}0.02765 \\
0.00099 \\
0.00000\end{array}$ \\
\hline$\frac{0}{\frac{0}{0}}$ & $\begin{array}{l}A \\
I_{T} \\
Y_{T}\end{array}$ & $\begin{array}{l}0.01605 \\
0.00053 \\
0.22676\end{array}$ & $\begin{array}{l}0.02171 \\
0.00062 \\
0.18848\end{array}$ & $\begin{array}{l}0.02171 \\
0.00062 \\
0.18848\end{array}$ & $\begin{array}{l}0.01794 \\
0.00239 \\
0.48211\end{array}$ & $\begin{array}{l}0.01699 \\
0.00204 \\
0.90778\end{array}$ & $\begin{array}{l}0.01510 \\
0.00020 \\
1.16125\end{array}$ & $\begin{array}{l}0.01510 \\
0.00006 \\
1.25125\end{array}$ & $\begin{array}{l}0.00000 \\
0.00000 \\
0.00000\end{array}$ & $\begin{array}{l}0.00000 \\
0.00000 \\
0.00000\end{array}$ \\
\hline
\end{tabular}

Table 2. Separate examples for the set individual effects

\begin{tabular}{|c|c|c|c|}
\hline & \multicolumn{2}{|c|}{ Time interval } & \multirow{2}{*}{$\begin{array}{l}\text { Excluded parts of the cross-section in the initial interval } \\
\qquad \Delta t_{1}\end{array}$} \\
\hline & $\Delta t_{1}=0$ & $\Delta t_{2}=\infty$ & \\
\hline \multirow{3}{*}{ 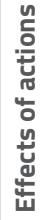 } & Example 1a: The structure's own weight & Concrete shrinkage & Cables (for all FE) \\
\hline & Example 1b: Prestressing the girder & Concrete shrinkage & Cables (for all FE) \\
\hline & Example 1c: Concrete shrinkage & Concrete shrinkage & \\
\hline
\end{tabular}

stressing of cables is finished, and when the calculated forces in cables are already acting, but prior to injection of pipes. In such conditions, the structure's own weight is assumed by the girder cross-section, without contribution of the cable geometry.

In [2] the problem is solved using the method of forces individually for every action. The solution is given assuming that the PS is an elastic material, and for strain resulting from the creep of concrete an algebraic relation has been adopted for medium stress. This is an approximate algebraic relation of theory of aging at constant elastic modulus of concrete.

The division of the girder to FEs and the position of nodes are shown in Figure 13. The geometric data on FEs and their layers are given in Table 1. Therefore, the top edge of the pavement slab has been chosen as the fixed axis of all FEs.
For the solution of this example, and for the sake of comparing the results and verifying the developed calculation model, including verification of computer program, three examples were formed in the first variation (three input files) in accordance with the set influences a), b) and c) (Table 2). The initial tensile stress in cables is calculated as $\sigma\left(t_{0}\right)=P / A_{p}$.

In the second variant, the task is solved using a single input file, because the present calculation model is generalized and enables including individual parts (layers) of cross-section in the active stress parts at various times. Also, any subsequent effects can be included in accordance with the staged realisation of the structure. At that, all abrupt (elastic) changes are introduced through fictitious intervals $(\Delta t=0)$. Therefore, two or three time intervals can be formed for the analysed example, depending on 
Table 3. Unified example for the set actions - two time intervals

\begin{tabular}{|c|c|c|}
\hline Interval & $\Delta t_{1}=0$ & $\Delta t_{2}=\infty$ \\
\hline Effects of actions & $\begin{array}{l}\text { a) Structure's own weight } \\
\text { b) Girder prestressing }\end{array}$ & $\begin{array}{c}\text { c) Concrete shrinkage } \\
\text { Concrete creep }\end{array}$ \\
\hline Excluded parts of the cross-section & Cables (for all FEs) & \\
\hline
\end{tabular}

Table 4. Unified example for the set actions - three time intervals

\begin{tabular}{|c|c|c|c|}
\hline Interval & $\Delta t_{1}=0$ & $\Delta t_{2}=0$ & $\Delta t_{3}=\infty$ \\
\hline Effects of actions & b) Girder prestressing & a) Structure's own weight & $\begin{array}{l}\text { c) Concrete shrinkage } \\
\text { Concrete creep }\end{array}$ \\
\hline Excluded parts of the cross-section & Cables (for all FEs) & Cables (for all FEs) & \\
\hline
\end{tabular}

the need for considering contributions of individual influences to the changes in the stress-strain state. In both cases, the last interval is finite, while the first one, or the first two, are fictitious (Tables 3 and 4).

In the first interval $\left(\Delta t_{1}=0\right)$ it is the steel girder and the concrete slab which are active, given that the prestressing cables are not yet injected and fail to make part of the composite crosssection, whereas the prestressing force is introduced as external
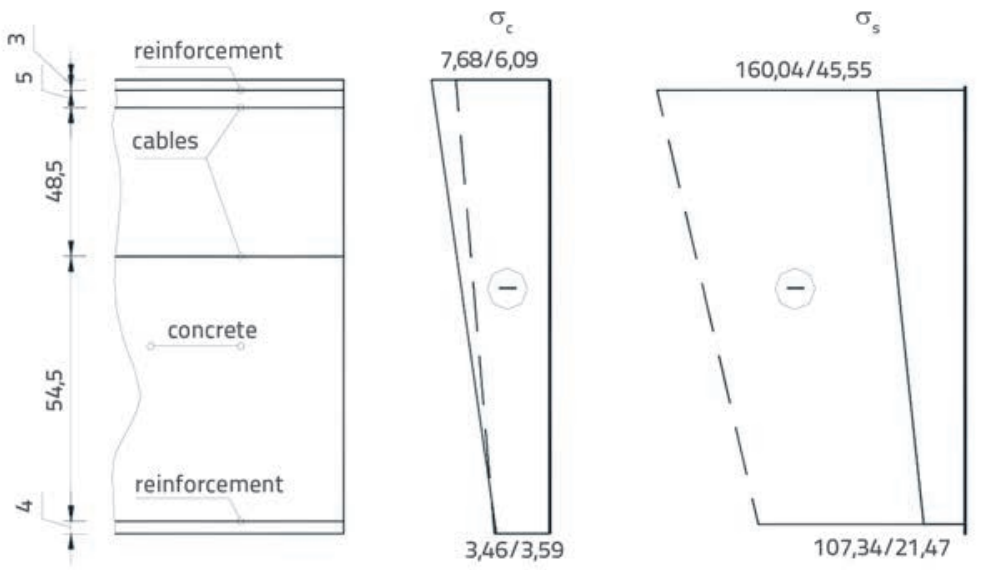

load $\sigma\left(t_{0}\right)=\mathrm{P} / \mathrm{A}_{\mathrm{p}}$. In this first interval loads under a) and b) can be introduced together. The second interval $\left(\Delta t_{2}=\infty\right)$ includes changes due to the shrinkage and creep of concrete, and the prestressing cables are included in the cross-section (Table 3). In the second case, when considering the influence of contribution of individual effects, the first and the second intervals are fictitious $\left(\Delta t_{1}=0\right.$ and $\left.\Delta t_{2}=0\right)$, which makes the basis for introduction of loads coming from prestressing and

Figure 14. Stresses in the cross-section of the girder above the central support [MPa]

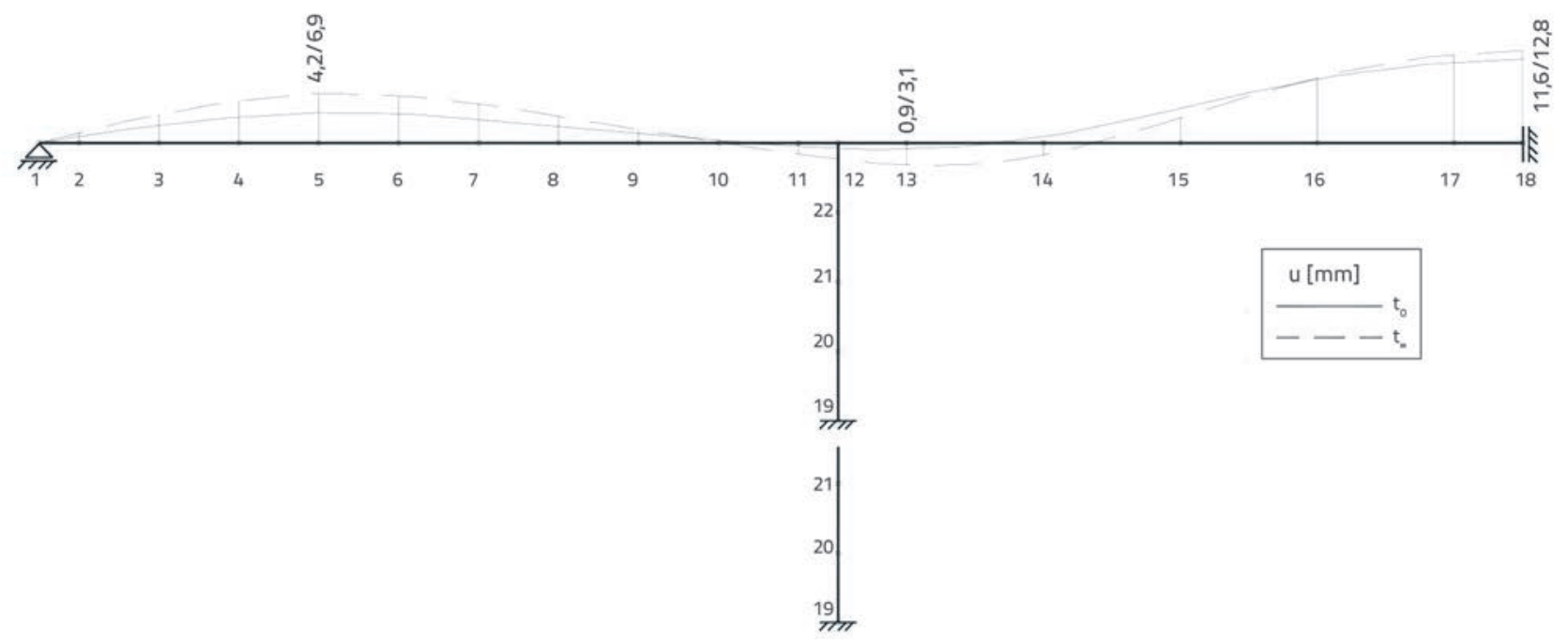

Figure 15. Deflections along the beam 
the own weight respectively, while the last (third) interval has the duration of $\left(\Delta t_{3}=\infty\right)$ and includes the viscous deformations induced by the shrinkage and creep of concrete (Table 4).

The results of stress for the bay girder's cross-section above the central bridge support are presented as representative examples (Figure 14).

After calculation, the values obtained for all variants are identical, regardless of whether the problem is solved individually or in a common file. Comparison of stress values with the values given in [2] reveals minimum deviations, which are the result of averaging the geometry of individual FEs and the approximate introduction of prestressing force in the structure via parabolic cables. These differences amount to less than $4 \%$ and do not pose any obstacle to the successful implementation of the developed calculation model even in such complex CS's.

This example shows redistribution of stresses in composite cross-sections due to shrinkage and creep of concrete over time. While the tension is released from concrete and cables, mild reinforcement takes over a significant portion of the stress. In this case, the upper reinforcement reaches the limit of stresses permitted for smooth steel, which is an increase of some $250 \%$, and so these changes should be taken into account at preliminary stages of design.

When it comes to deflection of the bay beam (Figure 15), it can be concluded that for the ultimate moment, due to shrinkage and creep of concrete, deflection in some parts of the beams has been increased by more than $60 \%$ compared to the initial elastic state.

\section{Conclusion}

When calculating complex CSs, it is important to take into account the contribution of rheology of concrete and the PS.

\section{REFERENCES}

[1] Pržulj, M.: Spregnute konstrukcije, Građevinska knjiga, Beograd, pp. 354, 1989.

[2] Đurić, M.: Teorija spregnutih i prethodno napregnutih konstrukcija, SANU, Beograd, pp. 183, 1963.

[3] Sekulović, M.: Metod konačnih elemenata, Građevinska knjiga, Beograd, 1988.

[4] Partov, D., Kantchev, V.: Time-dependent analysis of composite steel-concrete beams using integral equation of Volterra, according EUROCODE-4", Engineering Mechanics, 16 (2009) 5, pp. 367-392.

[5] Folić, R., Zenunović, D.: Spregnute konstrukcije čelik - beton, FTNMonografije 36, Novi Sad, pp. 362, 2009.

[6] Folić, R., Radonjanin, V., Malešev, M.: Design and Analysis of SteelConcrete Composite Structure, Introductinary - Invited paper on $6^{\text {th }}$ Greek National Conference on Metal Structures, Athens: Greek Association for Metal Structures, pp. 72-87, 2008.

[7] Folić, R., Cumbo, A.: Theoretic Bases for Analysis of Viscous Deformations in Composite Beams using the Finite Elements Method, Bulletins for Applied \& Computing Mathematics (BAM1770/2000 XCIII), Budapest, pp. 17-28, 2000.
The FEM method developed here, introducing layered rods and fictitious loads, enables generalisation of the procedure and the conduct of structural calculations as a whole system, including statically indeterminate structures, instead of being limited to the analysis of selected cross-sections only.

In technological procedures used during realisation of structures, where individual layers are introduced into the stress activity at different time intervals, changes in the load and all other changes can appropriately be included using the present calculation algorithm. More complex cases can also be analysed, such as any subsequent interventions aimed at strengthening and repairing of existing systems, as well as cases of exclusion of certain parts (for example, due to corrosion of reinforcement). The advantage of this algorithm is reflected in the use of computers and development of appropriate software enabling quick resolution of problems encountered in engineering practice, although it may also be quite useful for conducting research in this area of study.

It can be concluded based on the results of the presented numerical example that the CS design also requires analysis of viscoelastic properties of the material, because stresses and deformations in the elements change considerably over time. The compressed concrete layer is basically relaxed, while the actions are assumed by the steel girder and reinforcement, as cross-sectional strains and curvatures increase significantly with the passage of time.

\section{Acknowledgments}

The authors express their gratitude to the Ministry of Education, Science and Technological Development of the Republic of Serbia for the financial support provided under the projects TR36043.

[8] Folić, R., Tatomirović, M.: Spregnute betonske konstrukcije - I deo, Građevinski kalendar, Beograd, 31 (1999), pp. 289-386.

[9] Chiorino, M.A.: Structural effects of time-dependent behaviour of concrete, ICJ The Indian Concrete Journal, Theme: Creep and Shrinkage, Guest Editorial, Maharashtra, India,86 (2012) 12, pp. 3-6.

[10] Chiorino, M.A., Carreira, D.J.: Factors affecting creep and shrinkage os hardened concrete and guide for modelling, ICJ The Indian Concrete Journal, Theme: Creep and Shrinkage, A state-of-the-art report on international recommendations and scientific debate, Maharashtra, India, 86 (2012) 12, pp. 11-24.

[11] Folić, R., Popović, B.: Parcijalno prethodno napregnute konstrukcije, FTN-Monografije, Novi Sad, 27 (2008), pp. 212.

[12] Lazić, J.: Približna teorija spregnutih i prethodno napregnutih konstrukcija, Naučna knjiga, Beograd, 1988.

[13] Cumbo, A., Folić, R.: Primjena metode konačnih elemenata za analizu uticaja reoloških svojstava na stanje napona i deformacija spregnutih konstrukcija, Građevinski kalendar, 36 (2004), pp. 203255. 